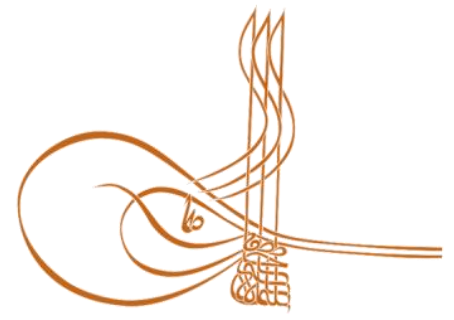

www.turkishstudies.net/social
Turkish Studies-Social Sciences

eISSN: 2667-5617

Research Article / Araștırma Makalesi

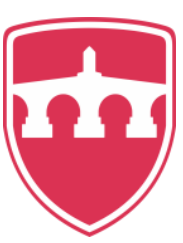

INTERNATIONAL

BALKAN

UNIVERSITY

Sponsored by IBU

\title{
Sağlık Kurumlarında Sağlık Hizmetleri ve Genel İdari Hizmetler Sınıfı Arasındaki İletişim Sorunları
}

\author{
Communication Problems Between Health Services and General Administriative Services in Health \\ Institutions
}

\author{
Zuhal Sönmez ${ }^{*}$ Ümit Naldöken**
}

\begin{abstract}
Communication; the natural result of life, existence and awareness. The main purpose of communication is to be understood. To understand and to be understood, these are the main reasons why we communicate. Our study, which includes communication and more specifically organizational communication refers to the abyss in the literature which directly points out the communicational problems and disabilities between the different classes inside the health sector. A questionnaire was applied to the employees of Sivas Numune Hospital to examine the communicational relation status between HS (Health Services) class and GAS (General Administrative Services) class staff as this is the main object of this study. After a brief description of notions that are used in this study, the methodology and findings of the study have been included. As the data collecting tool, the questionnaire has been implemented. Acceptable 414 questionnaires have been considered into our praxis. Percentage distributions of the data that have been uploaded to the SPSS program, the relationship between each other and their significance levels were examined. As a result of the study, a semantic relationship was observed between these two classes when they were evaluated in terms of mutual success between the general administrative services class and health care personnel. When the putting themselves together of our sample group working in general administration and health service class were examined, it was seen that the relationship between them was meaningful. Likewise, there was a semantic expression in the sharing of knowledge between these two groups. There is no semantic relationship between health services and administrative services class workers about mutually sharing of their matters. Again, it was observed that there was no semantic expression between the two groups' employees about being open to criticsm against each other.
\end{abstract}

Structured Abstract: It will be possible for the personnel who are employed in health care institutions to communicate well with their relatives of patients or patients, and first of all, they will be able to make their

\footnotetext{
* T.C. Sağlık Bakanlığı, Sivas İl Sağlık Müdürlüğü

Republic of Tukey, Ministry of Healty, Sivas Provincial Health Directorate

ORCID 0000-0002-0946-7147

zuhal.sonmez@saglik.gov.tr

*** Dr. Öğr. Üyesi, Sivas Cumhuriyet Üniversitesi, Sağlık Bilimleri Fakültesi, Sağlık Yönetimi Bölümü

Asst. Prof. Dr., Sivas Cumhuriyet University, Faculty of Health Sclences, Health Management Department

ORCID 0000-0003-1295-8358

unaldoken@cumhuriyet.edu.tr

Cite as/ Atıf: Sönmez, Z., Naldöken, Ü. (2020). Sağlık Kurumlarında Sağlık Hizmetleri ve Genel İdari Hizmetler Sınıfı

$\begin{array}{lllll}\text { Arasindaki İletişim } & \text { Sorunlar1, } & \text { Turkish } & \text { Studies-Social, } & 15(1),\end{array}$

https://dx.doi.org/10.29228/TurkishStudies.36844

Received/Geliş: 02 September/Eylül 2019

Accepted/Kabul: 25 February/Şubat 2020

Copyright $\subset$ INTAC LTD, Turkey 
own communication healthy. It is inevitable that the staff who are at peace with themselves and their colleagues bring success to their institution, as well as to bring patient satisfaction to the highest levels. It is also important because the work that processes the communication that guides the image and future of the institution is one of the rare studies carried out in this field. Another factor that makes the study important is that it guides similar studies to be done after that and sheds light on their paths.

A number of studies have been conducted on the health sector of communication, which is mentioned in a brief and emphasised importance. When the literature is examined, it is observed that many issues such as patient personnel communication, patient satisfaction, quality of service are studied similarly by different people and on different dates. It has been determined that there is no study on Communication Issues between The Health Services Class (HS) and General Administrative Services Class (GAS) Personnel in the literature. Accordingly, the necessary documents and researches are used in the best and right way to use the existing facilities in the best and right way, the subject selection of the study intended to fill a gap in the literature "Health Services Class (and General Administrative Services Class Communication Issues between their staff" has been decided.

It is in the working screening model on communication problems between health services class and general administrative services class personnel in health institutions. The scanning model is to investigate the case or individual directly based on various previously kept records (documents, statistics, images) as well as the incident or individual itself can be examined. The study was conducted in a general screening model, a scanning model made on the entire universe or a sample, in order to reach a general judgment about the universe in a universe of numerous elements. Singual or relational scans can also be performed in this model.

Our study aimed at examining communication problems between Health Services Class and General Administrative Services Class Personnel in Health Institutions, a survey was applied to employees at Sivas Numune Hospital.

In the effort to produce its own existence, the person enters into social, economic and political relations with other people during their production activities. Communication, thought consciousness and the production of linguistic activities are part and consequence of people's manufacturing activities. Unlike other creatures, human beings produce their own individual and social presence in a manner that depends on social production relationships and business. This process inevitably leads to the emergence of a language and communication relationship. Communication between people takes various forms depending on historical and social conditions. The most obvious of these forms is mass communication in conditions that develop through technological tools that are evolving today. In the 20th century, we can call it the age of technology and communication, and thanks to the incredible advances in computers and technology, people's communication with each other has become extremely easy to record.

It is very important that employees communicate on time and effectively in market conditions where the success of the institution is in the nature of the satisfaction gained from the employee's job and the competitive conditions are brutalized. On the other hand, employees with high institutional commitment striving to achieve these goals and strive more than they expected to achieve these goals increase the competitiveness of the institution. Without any question marks in his mind, the employee who reaches the information he wants and needs in a timely and adequate amount of information, with the right media, will increase his confidence in the first place and then his faith and commitment to his institution. This will affect the commitment to the institution and the satisfaction of the customer, which is the fact that communication is at its core.

Based on the philosophy of "Satisfaction begins internally", the communication of individuals working in each institution first with themselves, then the communication with the environment is tried to explain as a result of our study sivas Numune hospital, health services class and general administrative The communication of the personnel working in the services class was examined and a number of results were produced. In accordance with these results, some recommendations have been included.

The majority of the participants who were the subject of our study are women. The majority of our participants are 31-35 years old (the number of men is also too much to be underestimated, and the nature of the study has been ensured to be balanced in terms of gender). The majority of those who participated in our survey were midwives and nurses. The vast majority of our sample group is in the health care class. The 
majority of participants have been in the profession for less than 5 years. Our number of participants who have been in this profession for a while between 6-10 years is insignificant.

The vast majority of participants have been working in this institution for less than 5 years. The vast majority of our sample group is undergraduate. It has been observed that the vast majority of our sample group has previously studied communication. On the scale and asked to the participants, HS and GAS employees mutually share their problems, HS and GAS employees mutually share their achievements, HS and GAS employees mutually respect each other, HS and GAS employees Employees relied on each other mutually, HS and GAS employees are open to criticism against each other, HS and GAS employees try to understand themselves by putting each other in place during communication, HS and GAS employees they are tolerant of differences between political views, culture, etc., HS and GAS employees pay attention to face-to-face communication between them, HS and GAS employees mutually share their information, HS and GAS employees at social meetings They come together, there is a positive communication environment between HS and GAS employees, which do not allow gossip, informal communication channels are open between HS and GAS employees, HS and GAS employees have close relationshipbetween them they make a sincere effort to maintain, HS and GAS understand the work and work objectives of the employees in the same way, HS and GAS employees are good listeners in communication between them, the vast majority of our sampling group to their judgments, and sometimes, and they have often given answers in the form of. According to the results in this table, it is possible to say that there is no communication problem between health services and general administrative services class employees HS and GAS employees of the participants try to highlight each other's positive behavior, and even if their negative responses to their judgment appear to be in the majority, they have not had an overwhelming advantage over the positive response options. T-testing was used for independent groups to test whether communication problems between participants differ edifies significantly. As a result of this test, it was determined that there was a meaningful relationship between the mutual sharing of the achievements of the two different classes.

Koç (2017) As a result of his study on communication in health institutions, 53\% of the participants were women. In our study, $54.6 \%$ of the participants are women. In terms of gender, this study is similar. In our study, $43.7 \%$ of the participants' educational status was determined as a license. In Koç's work, $45 \%$ of them are graduates of teaching. In terms of education, these two studies differ.

In his study, Yağbasan and Cakar (2006) used professional language as the cause of the communication problem between the patient and the doctor, causing communication problems between them. In our study, it was determined that the doctors who entered the health service class shared their information with the personnel who served as general administrative services.

Hoşgör (2014) found the respect of doctors in the health service class in his study positive and positive with other employees. In our study, a similar result was found and the SH class respected other employees. The situation in which these two studies contrast together, in our study, it was seen that the HS class shared its achievements in some cases with other friends, while the tolerance study showed that doctors did not share their success with anyone.

In the study, it is seen that the communication of the personnel in their own right, regardless of the position in health care, is good, but a number of studies can be carried out by the authorities to take this communication to a higher level.

Keywords: Communication, Organizational Communication.

Öz: İletișim; yașıyor olmanın, var olmanın ve farkında olmanın doğal sonucudur. İletișim kurmanın asıl amacı anlaşılabilir olmaktır. Anlamak ve anlaşılmak için iletişim kurulur. İletişim ve örgüt içi iletişimi konu alan çalışmamız. Literatürdeki boşluk görülerek sağlık sektöründe farklı sınıflar arasındaki iletişim durumlarını inceleyen çalışmamızın konu ve yöntem seçiminden sonra. Çalışmanın tabiatı gereği Sivas Numune Hastanesi çalışanlarına anket uygulanmış ve SH sınıfı ve GiH sınıfı personelleri arasındaki iletişim durumu incelenmişsir. Çalışmanın konusuna yakınlık gösteren birçok kavramın kısa tanımı yapıldıktan sonra çalıșmanın yöntemi ve bulgular kısmına yer verilmiştir. Veri toplama aracı olarak anket uygulanmıştır. Geçerli görülen anketlerden 414 tanesi uygulamamıza dahil edilmiştir. SPSS paket programına yüklenen verilerin yüzdelik dağılımları, birbirleriyle olan ilișkileri ve anlamlılık düzeyleri incelenmiștir. Çalıșma sonucunda, genel idari hizmetler sınıfı 
ve sağlık hizmetleri personeli arasında karışlıklı olarak başarılarını paylaşma durumlarına bakıldığında bu iki sınıf arasında anlamlı bir fark görülmüştür. Geneli idare ve sağlık hizmeti sınıfında görev yapan örneklem gurubumuzun kendilerini birbirlerinin yerine koyma durumları incelendiğinde aralarındaki ilişkinin anlamlı bir fark olduğu görülmüştür. Benzer şekilde bu iki grup arasında, bilgilerini birbirleriyle paylaşma durumlarını da anlamlı bir fark görülmüştür. Sağlık hizmetleri ve idari hizmetler sınıfı çalışanlarının sorunlarını karşılıklı olarak paylaşma durumlarına bakıldığında aralarında anlamlı bir fark görülmemiştir. Yine bu iki grup çalışanları arasında birbirlerine karşı eleştiriye açık olma durumları arasında da anlamlı bir fark olmadığı görülmüştür.

Anahtar Kelimeler: İletişim, Örgütsel İletişim.

\section{Giriş}

İnsanoğlu dünyaya gelişinden itibaren sürekli bir gelişime ve hayat mücadelesi vermeye mecburdur. İnsanoğlunun gelişime duyduğu ihtiyacı, onun tek başına yaşama ihtimalini ortadan kaldırmış ve insanları topluluklar halinde yaşamaya mecbur bırakmıştır. İnsanoğlu önce toplumun en küçük yapı taşı olarak kabul edilen ailede sosyalleşerek paylaşımlarını yaşamaya başlar sonraki evrelerde ise iş hayatında iş ve sosyal çevresiyle kaynaşarak gelişimini tamamlar. Toplum içinde yaşamayı kaçınılmaz kılmak birtakım paylaşımları, ortak duygu düşünce ve yaşantıları beraberinde getirmektedir. Kişinin ilk olarak ailesinden aldığı iletişim ve sosyalleşme eğitimi sosyo-ekonomik değişkenlere göre farklılık arz etmektedir, bilhassa kişilerin rol ve statülerinin kendilerine verdiği egoyla insanlar arasında bir takım iletişim problemleri ortaya çıkmaktadır. Bu ve buna benzer sorunlarla hemen hemen toplumun her evresinde karşılaşmak mümkündür (Aslan, 2004: 30-38).

İletişimin kökeninde, insanın diğer insanlar; çevre, toplumsal değer, tutum ve davranışlar hakkında bilgi edinip, kendini güçlü ve güven içinde hissetme arzusu yatmaktadır. Örgütsel iletişim açısından bakıldığında ise çalışanların kurum içinde ihtiyaçlarını tatmin etmek için bilgiye ihtiyaç duydukları (yöneldiklerini) ifade edilebilir. Aynı çatı altında yaşamaya mecbur kalan bir topluluğa mensup insanların birbirlerini anlama, tanıma, sevme, güvenme vb gibi zorunlu ihtiyaçlarını karşılamak amacıyla birbiriyle iletişim içinde olmalan kaçınılmaz bir gerçektir. Nitekim insanlar birbirleriyle olan iletişimleri sayesinde ortak paylaşımları olabilir ve dostluk, sevgi tohumları filizlenmiş olur. Örgütlerde, kurumlarda ortak amaç için görev yapan kişiler arasındaki iletişimin iyi olması başarının ve mutluluğun simgesi olarak gösterilse yeridir. Diğer bütün kurumlarda olduğu gibi sağlık hizmeti sunan kurumlarda da iletişimin önemi son derece büyüktür. Hata ve gecikme ihtimalinin söz konusu olamayacağı insan sağlığına hizmet veren kurumlarda, iletişimin hayati değer taşıdığı söylenirse hiçte abartılmış olmayacaktır. Sağlık hizmeti sunan kurumların diğer kurumlara oranla hata yapma ihtimalleri yoktur, hatasız işlemesinin altındaki en temel etken ise iletişimdir (Atakan, 2015).

İnsanlara 24 saat kusursuz hizmet sunan kurumlarda, sahnenin önünde ve arkasında ortak amaç için çalışan büyük bir insan topluluğu vardır. Bu personeller içinde de iletişim problemlerinin yaşanmaması ve birbirleriyle olan uyumu ve diyaloglanı onların başarısına etki ederek kusursuzluğu getirmesi gerekmektedir (Ergüden, 2015).

Bilindiği gibi sağlık canlıların hayatındaki en önemli yapı taşlarından biridir. Birey grup ve toplumların sosyal ve psikolojik yönlerini de ilgilendiren bu kavramın tanımı farklı kişiler tarafından farklı şekillerde yapılmış olsa bile ortak kabul gören tanımlar birkaç ana tema üzerinedir. Bunlardan bazılarına bakılacak olursa; "Bazı bireylere göre sağlık, genel olarak hastalık durumunun olmaması" olarak ifade edilmektedir (Türkmendağ, 2012). Hekimler hastalığı, normalden sapma hali olarak kısa ve öz bir şekilde ifade etmişlerdir. Dünya Sağlık Örgütü sağlığın tanımını "sağlık sadece hastalık ve maluliyetin yokluğu olmadan bedenen ve ruhen sosyal açıdan tam bir iyilik halidir" şeklinde yapmıştır (Türkmendağ, 2012). 
Sağlı, insanların öğrenim durumları, alışkanlıkları, inançları, gereksinimlerini nasıl sağlayabildikleri, sağlık için ayırabildikleri kaynakları ve kişinin hayat kalitesiyle saptanan multifaktöriyel bir netice olarak düşünülebilir. Dolayısıyla hastalıklara yaklaşım da hastalığın çeşidi, ciddiyeti, hastalık sebepleriyle ilgili daha eskiden oluşan inanışlar, mümkün tedavi seçeneklerinin kabul edilebilirliği ve tedavinin faydasının görülmesi gibi sayısız faktörleri kapsamaktadır. Kişilerin sağlık ve hastalık kavramlarıyla ilgili algıları onların çeşitli hallerdeki sağlık arama davranışlarını etkileyebilir. Yapılan araştırmalar, bu algıların ve davranışların pek çok faktör tarafından etkilendiğini göstermektedir (Aslan, 2004).

Sağlık hizmetleri; Dünya Sağlık Örgütü (DSÖ) tarafindan, "belirli sağlık kuruluşlarında değişik tip sağlik personelinden yararlanarak toplumun gereksinim ve isteklerine göre değişen amaçları gerçekleştirmek ve böylece kişilerin ve toplumun sağlık bakımını her türlü koruyucu ve tedavi edici etkinliklerle sağlamak üzere ülke çapında örgütlenmiş kalıcı bir sistem" olarak tanımlamaktadır (Kavuncubaşı, 2000).

Sağlik hizmetleri ülkelerin sosyo-ekonomik alandaki gelişmişlik düzeyini gösteren temel göstergelerin başında gelmektedir. Tarih boyunca olduğu gibi ülkelerin gelir seviyesindeki artışlarla beraber sağlık giderlerine ayrılan bütçe artmaya başlamıştır (Kuzhan, 2009).

Bilindiği gibi sağlık sektörü; insanların sağlıklarını elde etmesi amacıyla, hizmet üreten, arz talep sistemine cevap veren, var olan bu sistemin içindeki kişi kurum ve statü vb tümünü belirtmek için kullanılan kapsayıcı bir kavramdır (Yüksek, 2012). Sağlık sektörü sağlık hizmetlerinde olduğu gibi sağlık elde etmek ve sağlığı korumak, sağlığı geliştirmek amacını taşımaktadır.

657 sayılı devlet memurları kanunu tanımlamasında yer alan, Genel İdare Hizmetleri sınıfi, kurumlarda yönetim icra, büro ve benzeri işleri gören personeli tanımlarken, sağlık hizmetleri sınıfı ise, sağlık hizmetlerinde mesleki eğitim görerek yetişmiş olan, tabip, eczacı, veteriner hekim, fizikoterapist, tıp teknoloji, ebe, hemşire, sağlık memuru, sosyal hizmetler uzmanı, biyolog, psikolog, diyetçi, sağlı mühendisi, sağlık fizikçisi, sağlık idarecisi, ebe, hemşire ve yardımcısı (fizik tedavi, laboratuvar, eczası, diş anestezi, röntgen teknisyenleri ve yardımcıları, çevre sağlı̆̆ 1 ve toplum sağlığı) sağlık memuru vb personeli kapsamaktadır (Ertaş, 2014).

\section{1.Çalıșmanın Konu Seçimi}

Yukarıda kısaca bahsedilen ve önemi vurgulanan iletişim örgüt içi ve dışındaki olan insan ilişkilerinin sağlık sektöründe ki uygulanışını konu alan birçok çalışma yapılmıştır. Literatür incelendiğinde sağlık sektöründe, hasta personel iletişimi, hasta memnuniyeti, hizmet kalitesi gibi birçok konunun farklı kişilerce ve farklı tarihlerde birbirine benzer olarak çalışıldığ görülmektedir (Türkmendağ, 2012). Literatürdeki Sağlık Hizmetleri Sınıfi ve Genel İdari Hizmetler Sınıfı Personelleri Arasındaki İletişim Sorunlarını konu alan bir çalışmanın olmadığı tespit edilmiştir (Genç, 2011, Gölova vd, 2012, Örücü, 2012). Bu doğrultuda gerekli belgeler ve araştırmalar yapılarak varolan imkanları da en iyi ve doğru şekilde kullanılarak, literatürdeki bir boşluğu doldurması amaçlanan çalışmanın konu seçimine "Sağlık Hizmetleri Sınıfı ve Genel İdari Hizmetler Sınıfı Personelleri Arasındaki İletişim Sorunları” olarak karar verilmiştir.

\section{2.Çalışmanın Amacı ve Önemi}

Toplumsal bir varlık olan insanlar birbirleriyle iletişim kurabilmek amacıyla yüzyıllardır değişik yöntemler kullanmışlardır. Sosyal bir çevrede varolup hayatını sürdüren insanlar, farkında olsun ya da olmasın sürekli birileriyle iletişim halindedirler. İletişimin olumsuz ve etkisiz olduğu toplumlarda veya kurumlarda bir takım aksaklıklar ve başarısızlıklar meydana gelecektir. Tabiatı gereği sağlık hizmeti sunan kurumlarda bu ve buna benzer aksaklıkların yaşanma ihtimali bile düşünülmemelidir. Sağlık sektöründeki personelin çevresiyle olan iletişimi temalı çalışmanın asıl amacı, kurum içerisinde personelin ilişkilerini inceleyerek birbirleriyle olan iletişimlerine bakmaktır. 
$\mathrm{Bu}$ ana amacın yanında literatürdeki boşluğu doldurması ve bundan sonraki araştırmacılara yol gösterici nitelikte olması amaçlanmıştır.

Tam bu noktada çalışmanın önemi gün yüzüne çıkmaktadır. Sağlık hizmeti sunan kurumlarda görev alan personellerin hasta veya hasta yakınlarıyla iyi iletişim kurmaları öncelikle kendi içlerindeki iletişimlerini sağlıkı bir hale getirmeleriyle mümkün olacaktır. Kendiyle ve mesai arkadaşlarıyla barışık olan personellerin kurumuna başarı getirmesinin yanı sıra hasta memnuniyetini de üst seviyelere taşıması kaçınılmaz bir gerçektir. Kurumun imajına ve geleceğine yön veren iletişim konusunu işleyen çalışmanın bu alanda yapılan nadir çalışmalardan biri olması sebebiyle ayrıca bir öneme sahiptir. Çalışmayı önemli kılan bir başka unsur ise bundan sonra yapılacak olan benzer çalışmalara kılavuz olması ve yollarına 1şık tutmasıdır.

\section{Araştırma}

\subsection{Araştırmanın Modeli}

Bilimsel araştırmalarda kullanılacak yöntem çalışmanın modelini de belirlemiş olacaktır. Kullanılacak yöntem ve uyulacak modelleme, çalışmanın bilimsel bir temele oturtulması açısından oldukça önemlidir. Farklı yöntemler kullanılarak doğru sonuç elde edilebilmektedir ancak önemli olan kullanılacak yöntemin araştırmanın konusuna uygun olmasıdır.

Sağlık Kurumlarında Sağlık Hizmetleri Sınıfı ve Genel İdari Hizmetler Sınıfı Personelleri Arasındaki İletişim Sorunlarını konu alan çalışma tarama modelindedir. Tarama modeli araştırmada olayın veya bireyin doğrudan kendisinin incelenebileceği gibi önceden tutulmuş çeşitli kayıtlara (belge, istatistik, resim vb) dayalı olarak araştırma yapılmasıdır. (Karataş, 2012: 47)

Çalışma, "çok sayıda elemandan oluşan bir evrende, evren hakkında genel bir yargıya varmak amacıyla, evrenin tümü ya da bir örneklem üzerinde yapılan" tarama modeli olan genel tarama modelinde yapılmıştır. Bu model de tekil veya ilişkisel taramalar yapılabilmektedir.

\subsection{Evren ve Örneklem Seçimi}

Sivas İli Kamu Hastaneleri Birliği Genel Sekreterliğine bağl1 Numune Hastanesinde 1617 Sağlık Hizmetleri Sınıfı personeli, 349 Genel İdari Hizmetler Sınıfı personeli olmak üzere toplam 1966 personel araştırmanın evrenini oluşturmaktadır.

$n n=N . t^{2} \cdot \sigma^{2} /(N-1) \cdot d^{2}+t^{2} . \sigma^{2}$ formülüne göre hesaplanmış ve Sağl1k Hizmetleri Sınıfi için araştırmanın örneklemi 311 olarak bulunmuştur.

Numune Hastanesine Sağlık Hizmetleri Sınıfında görev yapan 1617 kişiden 311 çalışanın çalışmaya dahil edilmesi uygun görüldü. Bunun içinde rastgele sayılar tablosu kullanılarak bir başlangıç sayısı belirlendi ve isme göre alfabetik olarak sıralanmış listeden, A harfinden başlayarak her 5 bireyde 1 birey örnekleme dahil edilmiş, istenen sayıya ulaşmak için aynı işlemi sonraki harflerle tekrarlanmıştır.

$\mathrm{n}=\mathrm{N} \cdot \mathrm{t}^{2} \cdot \sigma^{2} /(\mathrm{N}-1) \cdot \mathrm{d}^{2}+\mathrm{t}^{2} \cdot \sigma^{2}$ formülüne göre hesaplanmış ve Genel İdari Hizmetleri Sınıfı için araştırmanın örneklemi 184 olarak bulunmuştur.

Numune Hastanesinde Genel İdari Hizmetleri Sınıfında 349 kişiden 184 bireyi örnekleme alınmasına karar verildi bu 184 bireyin seçimi yapılırken de sistematik örnekleme yapıldı. Bunun içinde rastgele sayılar tablosu kullanılarak bir başlangıç sayısı belirlendi ve isme göre alfabetik olarak sıralanmış listeden her 5 kişiden 1 kişi örnek alındı, örneklem sayısının hesaplanan sayıya ulaşması için aynı işlem diğer harfler içinde uygulanarak örneklem gurubu oluşturuldu.

495 kişilik örneklem gurubumuza dağıtılan anketlerden geçerli cevap verilerek doldurulmuş olan 414 anket, çalışmaya dahil edilmiştir. 


\subsection{Veri Toplama Araçları}

Çalışmada veri toplama aracı olarak anket uygulanmıştır.

1. Kişisel Bilgi Formu: Araştırma alan araştırması özelliği taşımaktadır. Bu doğrultuda araştırmada birincil veri toplanmaya çalışılmış ve bu amaçla veri toplama aracı olarak anket seçilmiştir. Alan araştırmasında kullanılan anket formu iki bölümden oluşmaktadır. Anket formunun ilk bölümünde katılımcıların demografik özelliklerinin belirlenmesi ve bu özelliklere göre iletişim sorunlarının incelenmesi amaciyla anket formunda 8 demografik ve kategorik soru yer almaktadır.

2.Sağlık Çalışanları ve Genel İdari Hizmetler Sınıfı Çalışanları Arasındaki İletişim Sorunları Ölçeği Anketi: Anket formunun ikinci bölümünde ise sağlık kuruluşlarında çalışan genel idari hizmetler personelleri ve sağlık personeli arasındaki iletişim sorunlarının belirlenmesi amacıyla sorulmuş 16 adet Likert ölçekte hazırlanmış soru yer almaktadır. Ölçekte yer alan ifadeler 1-hiçbir zaman, 5-herzaman aralığında ölçülmüştür. Çalışmada kullanılan ölçek, Korkut (1996) tarafindan kullanılan ölçeğin sağlık çalışanlarına uyarlanarak ve pilot çalışma sonucunda elde edilen bilgilerin araştırmacı tarafından değerlendirilmesi sonucunda eklenen soruların birleşiminden araştırmacı tarafından oluşturulmuştur.

\subsection{Verilerin Değerlendirilmesi (İstatistiksel Yöntem)}

Çalışmada elde edilen veriler SPSS (ver: 22.0) programına yüklenerek verilerin parametrik test varsayımları yerine getirildiğinde (Kolmogorof-Simirnov) iki ortalama arasındaki farkın önemlilik testi, Varyans analizi, Tukey testi, parametrik test varsayımları yerine getirilmediğinde Man Whitney U testi, Kruskal Wallis testi ve sayımla elde edilen veriler değerlendirilirken Ki-kare kullanılarak ve yanılma düzeyi 0,05 olarak alınmıştır..

\subsection{Araştırmanın Varsayımları}

$\checkmark$ Araştırmada ele alınan örneklemin evreni yansıttığı,

$\checkmark$ Anket sorularının çalışmanın amacına uygun olduğu ve gerçeği yansıttığı,

$\checkmark$ Ankette sorulan sorularının içeriği yeterli olduğu

$\checkmark \quad$ Katılımcıların ankete verdikleri cevapların doğru olduğu çalışmanın varsayımlarıdır.

\section{Bulgular}

Sağlık Kurumlarında Sağlık Hizmetleri Sınıfı ve Genel İdari Hizmetler Sınıfı Personelleri Arasındaki İletişim Sorunlarının incelenmesini amaçlayan çalışmamız Sivas Numune Hastanesinde çalışanlara anket uygulanmıştır. Uygulanan anketlerin yüzdelik dağılımları ve t testi sonuçları çalışmanın bu bölümünde gösterilmiştir.

Tablo 1: Katılımcıların Cinsiyetlerine göre dağılımları

\begin{tabular}{lll}
\hline & Sayı & Yüzde \\
\hline Erkek & 188 & 45,4 \\
Kadın & 226 & 54,6 \\
Toplam & 414 & 100,0 \\
\hline
\end{tabular}

Tablodan da görüleceği gibi katılımcıların \%45,4'lük k1smı erkeklerden oluşurken, \%54,6'lık kısmı kadınlardan oluşmaktadır. Örneklem gurubumuzun büyük çoğunluğunu kadınların oluşturduğu söylenebilir.

Tablo 2: Katılımcıların Yaşlarına göre dağılımları

\begin{tabular}{lcc}
\hline & Kişi & Yüzde (\%) \\
\hline $\mathbf{2 5}$ yaş altı & 66 & 15,9 \\
$\mathbf{2 6 - 3 0}$ yaş & 65 & 15,7 \\
$\mathbf{3 1 - 3 5}$ yaș & 88 & 21,3 \\
$\mathbf{3 6 - 4 0}$ yaș & 67 & 16,2 \\
\hline
\end{tabular}

www.turkishstudies.net/social 


\begin{tabular}{lcc}
\hline $\mathbf{4 1 - 4 5}$ yaş & 42 & 10,1 \\
46-50 yaş & 61 & 14,7 \\
$\mathbf{5 1}$ ve üzeri & 25 & 6,0 \\
Toplam & 414 & 100,0 \\
\hline
\end{tabular}

Tabloda görüldüğü gibi anketimize katılanlardan \%15,9'luk kısmı 25 yaş altındadır, \%15,7'lik kısmı 26-30 yaş arasında, \%21,3'lük kısmı 31-35 yaş arasında, \%16,2'lik kısmı 36-40 yaş arasında, \%10,1'lik kısmı 41-45 yaş arasında, \%14,7'lik kısmı 46-50 yaş arasında iken, \%6'lık kısım 51 ve üzeri yaş aralığındadır.

Tablo 3: Katılımcıların mesleklerine göre dağılımları

\begin{tabular}{lcc}
\hline & Kiși & Yüzde (\%) \\
\hline Hekim & 17 & 4,1 \\
Hemşire/ebe & 115 & 27,8 \\
VHKì & 59 & 14,3 \\
Hizmetli & 26 & 6,3 \\
Sağllk teknisyeni & 33 & 8,0 \\
Sağlık teknikeri & 70 & 16,9 \\
Memur & 44 & 10,6 \\
İş̧i & 12 & 2,9 \\
Diğer & 38 & 9,2 \\
Toplam & 414 & 100,0 \\
\hline
\end{tabular}

Tablodan görüleceği gibi katılımcıların meslekleri incelenmiştir. Buna göre anketimize katılanlardan \%4,1'lik kısım hekimlerden, \%27,8'lik kısım hemşire ebelerden, \%14,3'lük kısım VHKI'lerden, \%6,3'lük kısım hizmetlilerden, \%8'lik kısım sağlık teknisyeni, \%16,9'luk kısım sağlık teknikeri, \%2,9'luk kısım işçi, \%9,2'lik kısım diğer meslek gruplarına dahildir.

Tablo 4: Katılımcıların Hastanede çalışma sınıflarına göre dağılımları

\begin{tabular}{lcc}
\hline & Kişi & Yüzde (\%) \\
\hline Sağlık Hizmetleri Sınıfı & 249 & 60,1 \\
Genel İdari Hizmetleri & 165 & 39,9 \\
Toplam & 414 & 100,0 \\
\hline
\end{tabular}

Tablodan da anlaşılacağı gibi katılımcıların, hastanede çalışma sınıflarına göre dağılımları incelenmiştir. Buna göre sağlık hizmetleri sınıfında görev yapan katılımcılar \%60,1'lik kısımları oluştururken, genel idari hizmetler sınıfı \%39,9'luk kısımları oluşturmaktadır.

Tablo 5: Katılımcıların meslekteki çalıșma yılları

\begin{tabular}{lcc}
\hline & Kişi & Yüzde (\%) \\
\hline $\mathbf{5}$ yıl ve altı & 110 & 26,6 \\
$\mathbf{6 - 1 0}$ yll & 106 & 25,6 \\
$\mathbf{1 1 - 1 5}$ yll & 79 & 19,1 \\
$\mathbf{1 6 - 2 0}$ yıl & 53 & 12,8 \\
$\mathbf{2 1}$ ve üzeri & 66 & 15,9 \\
Toplam & 414 & 100,0 \\
\hline
\end{tabular}

Tabloda görüldüğü gibi katılımcıların meslekteki çalışma yılları incelenmiştir. Buna göre örneklem gurubumuzun \%26,6'lık kısm1 5 yıl ve daha kısa süre çalışmıştır. \%25,6' lik kısmı ise 6-10 yıl arasında, \%19,1'lik kısım ise 11-15 yıl arasında, \%12,8'lik kısım 16-20 yıldır çalışmakta iken, $\% 15,9^{\prime} l u k$ kısım ise 21 ve üzeri yıldır meslekte çalışmıştır. 
Tablo 6: Katılımcıların Kurumda çalışma sürelerinin dağılımı

\begin{tabular}{lcc}
\hline & Kişi & Yüzde (\%) \\
\hline $\mathbf{5}$ yll ve altı & 167 & 40,3 \\
$\mathbf{6 - 1 0}$ yıl & 102 & 24,6 \\
$\mathbf{1 1 - 1 5}$ yıl & 47 & 11,4 \\
$\mathbf{1 6 - 2 0}$ yıl & 54 & 13,0 \\
$\mathbf{2 1}$ ve üzeri & 44 & 10,6 \\
Toplam & 414 & 100,0 \\
\hline
\end{tabular}

Tabloda katılımcıların kurumda çalışma süreleri incelenmiştir. Buna göre $\% 40,3$ 'lük kısım 5 yıl ve altı süredir, \%24,6'lık kısım 6-10 yıldır, \%11,4'lük kısım 11-15 yıldır, \%13'lük kısım 16-20 yıldır, \%10,6’lık kısım ise 21 ve daha üzeri zamandır aynı kurumda çalışmaktadır.

Tablo 7: Katılımcıların Eğitim durumu

\begin{tabular}{lcc}
\hline & Kişi & Yüzde (\%) \\
\hline İlköğretim & 12 & 2,9 \\
Lise & 75 & 18,1 \\
Önlisans & 109 & 26,3 \\
Lisans & 181 & 43,7 \\
Lisansüstü & 37 & 8,9 \\
Toplam & 414 & 100,0 \\
\hline
\end{tabular}

Katılımcıların eğitim durumları incelendiğinde, örneklem gurubumuzun \%2,9'luk kısmı ilköğretim, \%18,1'lik kısmı Lise, \%26,3'lük kısım önlisans, \%43,7'lik kısım lisans \%8,9'luk kısım ise lisansüstü düzeyde eğitim almıştır.

Tablo 8: Katılımcıların iletişimle ilgili daha önce eğitim alma durumlarının incelenmesi

\begin{tabular}{lcc}
\hline & Kişi & Yüzde (\%) \\
\hline Evet & 252 & 60,9 \\
Hayır & 162 & 39,1 \\
Toplam & 414 & 100,0 \\
\hline
\end{tabular}

Yukarıdaki tabloda örneklem gurubumuzun daha önce iletişimle ilgili eğitim alma durumları incelenmiştir. Buna göre katılımcıların \%60,9'luk kısmı eğitim aldığın gösteren evet cevabını verirken, \%39,1'lik kısmı ise, iletişimle ilgili daha önce eğitim almadığını gösteren hayır cevabını vermişlerdir. Büyük çoğunluğun eğitim aldığını söylememiz mümkündür.

Tablo 9: Ölçeğe verilen cevapların yüzdelik dağılımları

\begin{tabular}{|c|c|c|c|c|c|c|c|}
\hline & & & $\begin{array}{l}\text { Hiçbir } \\
\text { zaman }\end{array}$ & Nadiren & Bazen & $\begin{array}{l}\text { Çoğu } \\
\text { zaman }\end{array}$ & $\begin{array}{c}\text { Her } \\
\text { zaman }\end{array}$ \\
\hline \multirow{4}{*}{$\begin{array}{l}\text { SH ile GïH çalışanları, sorunlarını } \\
\text { karşılıklı olarak paylaşırlar. }\end{array}$} & \multirow[t]{2}{*}{$\mathrm{SH}$} & $\%$ & 8,0 & 11,2 & 16,0 & 18,5 & 8,3 \\
\hline & & $\mathrm{n}$ & 33 & 46 & 66 & 77 & 34 \\
\hline & \multirow[t]{2}{*}{ GİH } & $\%$ & 5 & 5,5 & 13,0 & 9,3 & 5,2 \\
\hline & & $\mathrm{n}$ & 21 & 23 & 54 & 39 & 22 \\
\hline \multirow{4}{*}{$\begin{array}{l}\text { SH ile GïH çalışanları başarılarını } \\
\text { karşl1ıklı olarak paylaşırlar. }\end{array}$} & \multirow[t]{2}{*}{ SH } & $\%$ & 11,5 & 8,9 & 10,2 & 16,7 & 3,6 \\
\hline & & $\mathrm{n}$ & 48 & 37 & 42 & 69 & 15 \\
\hline & \multirow[t]{2}{*}{ GIH } & $\%$ & 5,6 & 6,2 & 18,5 & 5 & 3,6 \\
\hline & & $\mathrm{n}$ & 23 & 26 & 77 & 21 & 15 \\
\hline
\end{tabular}




\begin{tabular}{|c|c|c|c|c|c|c|c|}
\hline \multirow{4}{*}{$\begin{array}{l}\text { SH ile GIH çalışanları karşılıklı olarak } \\
\text { birbirine saygı gösterirler. }\end{array}$} & \multirow[t]{2}{*}{ SH } & $\%$ & 5,4 & 10,2 & 16,2 & 20,4 & 10 \\
\hline & & $\mathrm{n}$ & 22 & 42 & 67 & 84 & 41 \\
\hline & \multirow[t]{2}{*}{ GïH } & $\%$ & 1,6 & 7,7 & 8,0 & 16,1 & 4,5 \\
\hline & & $\mathrm{n}$ & 7 & 32 & 33 & 67 & 19 \\
\hline \multirow{4}{*}{$\begin{array}{l}\text { SH ile GïH çalışanları karşılıklı olarak } \\
\text { birbirlerine güvenirler. }\end{array}$} & \multirow[t]{2}{*}{ SH } & $\%$ & 5,3 & 11,5 & 18,7 & 20,0 & 8,1 \\
\hline & & $\mathrm{n}$ & 22 & 48 & 77 & 83 & 34 \\
\hline & \multirow[t]{2}{*}{ GïH } & $\%$ & 3,6 & 5,6 & 9,3 & 15,3 & 2,5 \\
\hline & & $\mathrm{n}$ & 15 & 23 & 39 & 63 & 10 \\
\hline \multirow{4}{*}{$\begin{array}{l}\text { SH ile GİH çalışanları, birbirlerine karş1 } \\
\text { eleştiriye açıtırlar. }\end{array}$} & \multirow[t]{2}{*}{ SH } & $\%$ & 8,5 & 14,1 & 18,5 & 17,4 & 8,5 \\
\hline & & $\mathrm{n}$ & 35 & 58 & 77 & 72 & 35 \\
\hline & \multirow[t]{2}{*}{ GïH } & $\%$ & 5,8 & 7,2 & 11,5 & 7,0 & 1,6 \\
\hline & & $\mathrm{n}$ & 24 & 30 & 48 & 29 & 7 \\
\hline \multirow{4}{*}{$\begin{array}{l}\text { SH ile GïH çalışanları iletişim Sırasında } \\
\text { kendilerini birbirlerinin yerine koyarak, } \\
\text { anlamaya çalışırlar. }\end{array}$} & \multirow[t]{2}{*}{ SH } & $\%$ & 14,6 & 14,5 & 21,4 & 13,6 & 6,3 \\
\hline & & $\mathrm{n}$ & 60 & 60 & 89 & 56 & 26 \\
\hline & \multirow[t]{2}{*}{ GİH } & $\%$ & 3,6 & 7,5 & 9,5 & 7,2 & 2,2 \\
\hline & & $\mathrm{n}$ & 15 & 31 & 39 & 30 & 9 \\
\hline \multirow{4}{*}{$\begin{array}{l}\text { SH ile GiH çalışanları arasındaki siyasi } \\
\text { görüş, kültür } \quad \text { vb. farklara karşı } \\
\text { hoşgörülüdürler. }\end{array}$} & \multirow[t]{2}{*}{ SH } & $\%$ & 6,6 & 16,2 & 18,6 & 16,4 & 8,0 \\
\hline & & $\mathrm{n}$ & 27 & 67 & 77 & 68 & 33 \\
\hline & \multirow[t]{2}{*}{ GïH } & $\%$ & 4,8 & 7,0 & 6,8 & 11,4 & 4,3 \\
\hline & & $\mathrm{n}$ & 20 & 29 & 28 & 47 & 18 \\
\hline \multirow{4}{*}{$\begin{array}{l}\text { SH ile GïH çalışanları, aralarında yüz } \\
\text { yüze iletişime önem verirler. }\end{array}$} & \multirow[t]{2}{*}{ SH } & $\%$ & 5,4 & 8,7 & 15,1 & 19,4 & 8,2 \\
\hline & & $\mathrm{n}$ & 22 & 36 & 63 & 80 & 34 \\
\hline & \multirow[t]{2}{*}{ GïH } & $\%$ & 1,6 & 11,6 & 12,3 & 13,8 & 3,9 \\
\hline & & $\mathrm{n}$ & 7 & 48 & 51 & 57 & 16 \\
\hline \multirow{4}{*}{$\begin{array}{l}\text { SH ile GİH çalışanları bilgilerini karşılıklı } \\
\text { olarak paylaşırlar. }\end{array}$} & \multirow[t]{2}{*}{ SH } & $\%$ & 5,2 & 1,5 & 20,4 & 16,5 & 7,4 \\
\hline & & $\mathrm{n}$ & 22 & 6 & 84 & 68 & 31 \\
\hline & \multirow[t]{2}{*}{ GïH } & $\%$ & 3,7 & 1,00 & 10,8 & 11,3 & 4,2 \\
\hline & & $\mathrm{n}$ & 15 & 4 & 45 & 47 & 17 \\
\hline SH ile GİH çalışanları sosyal içerikli & SH & $\%$ & 1,9 & 15,1 & 17,1 & 16,1 & 7,0 \\
\hline toplantılarda bir araya gelirler. & & $\mathrm{n}$ & 8 & 63 & 71 & 67 & 29 \\
\hline & GïH & $\%$ & 1,0 & 7,1 & 14,3 & 10,0 & 4,4 \\
\hline & & $\mathrm{n}$ & 4 & 29 & 59 & 41 & 18 \\
\hline SH ile GïH çalışanları arasında, & SH & $\%$ & 11,8 & 12,6 & 17,3 & 15,7 & 7,10 \\
\hline dedikoduya izin vermeyen, olumlu bir & & $\mathrm{n}$ & 49 & 52 & 72 & 65 & 29 \\
\hline iletişim ortamı vardır. & GïH & $\%$ & 4,9 & 10,8 & 11,4 & 5,3 & 3,00 \\
\hline & & $\mathrm{n}$ & 20 & 45 & 47 & 22 & 12 \\
\hline SH ile GİH çalışanları arasında, formal & SH & $\%$ & 9,10 & 14,7 & 17,4 & 16,2 & 6,3 \\
\hline iletişimin yanında informal iletişim & & $\mathrm{n}$ & 38 & 61 & 72 & 67 & 26 \\
\hline kanalları da açıktır. & GIH & $\%$ & 1,8 & 6,3 & 13,8 & 11,3 & 3,1 \\
\hline & & $\mathrm{n}$ & 7 & 26 & 57 & 47 & 13 \\
\hline SH ile GİH çalışanları aralarında yakın & SH & $\%$ & 7,4 & 15,5 & 13,0 & 16,3 & 6,7 \\
\hline ilişki sürdürme konusunda içten bir çaba & & $\mathrm{n}$ & 31 & 64 & 54 & 67 & 28 \\
\hline gösterirler. & GİH & $\%$ & 3,2 & 8,9 & 13,1 & 10,3 & 5,6 \\
\hline & & $\mathrm{n}$ & 13 & 37 & 54 & 43 & 23 \\
\hline SH ile GïH, çalışanları iş ve çalışma & SH & $\%$ & 5,4 & 11,6 & 21,3 & 10,0 & 5,3 \\
\hline amaçlarını aynı şekilde anlar ve yorumlar. & & $\mathrm{n}$ & 22 & 48 & 88 & 41 & 22 \\
\hline & GïH & $\%$ & 4,7 & 10,6 & 11,8 & 15,6 & 3,6 \\
\hline & & $\mathrm{n}$ & 19 & 44 & 49 & 65 & 15 \\
\hline & $\mathrm{SH}$ & $\%$ & 5 & 15,5 & 14,0 & 10,0 & 6,6 \\
\hline
\end{tabular}




\begin{tabular}{|c|c|c|c|c|c|c|c|}
\hline \multirow{3}{*}{$\begin{array}{l}\text { SH ile GïH çalışanları birbirlerinin } \\
\text { olumlu davranışlarını öne çıkarmaya } \\
\text { çalışırlar. }\end{array}$} & & $\mathrm{n}$ & 21 & 64 & 58 & 41 & 27 \\
\hline & \multirow[t]{2}{*}{ GïH } & $\%$ & 8,3 & 11,3 & 11,8 & 14,2 & 3,3 \\
\hline & & $\mathrm{n}$ & 34 & 47 & 49 & 59 & 14 \\
\hline \multirow{4}{*}{$\begin{array}{l}\text { SH ile GiH çalışanları aralarındaki } \\
\text { iletişimde iyi birer dinleyicidirler. }\end{array}$} & \multirow[t]{2}{*}{ SH } & $\%$ & 4,9 & 11,9 & 13,8 & 11,4 & 8,0 \\
\hline & & $\mathrm{n}$ & 20 & 49 & 57 & 47 & 33 \\
\hline & \multirow[t]{2}{*}{ GİH } & $\%$ & 6,5 & 8,9 & 11,8 & 18,3 & 4,6 \\
\hline & & $\mathrm{n}$ & 27 & 37 & 49 & 76 & 19 \\
\hline
\end{tabular}

Tabloda görüldüğü gibi katılımcıların ölçeğimize verdikleri cevapların şıklara göre (Hiçbir zaman, nadiren, bazen, çoğu zaman, her zaman) yüzdeleri ele alınmıştır. Buna göre anketimize katılanların büyük çoğunluğu SH ile GİH çalışanları arasında, karşılıklı olarak sorunları paylaştıkları bazen ve çoğu zaman olarak öne çıkmaktadır. Ölçeğimizin ikinci sorusu olan "SH ile GïH çalışanları başarılarını karşılıklı olarak paylaşırlar" yargısında da katılımcıların büyük kısmı bazen ve çoğu zaman cevabını vermişlerdir. Ölçeğimizin üçüncü sorusu olan "SH ile GİH çalışanları karşılıklı olarak birbirine saygı gösterirler." Yargısına verilen cevaplarda büyük oranda çoğu zaman ve bazen şekilde olmuştur. Ölçeğimizin dördüncü sorusu olan "SH ile GïH çalışanları karşılıklı olarak birbirlerine güvenirler." Yargısına da katılımcıların cevapları büyük ölçüde çoğu zaman olurken, bazen diyenlerin sayısı da küçümsenmeyecek kadar çoktur.

Ölçeğimizin beşinci sorusu olan "SH ile GİH çalışanları, birbirlerine karşı eleştiriye açıktırlar." Yargısına katılımcıların büyük kısmı bazen ve çoğu zaman cevabını vermişlerdir. Altıncı sorumuz olan "SH ile GİH çalışanları iletişim Sırasında kendilerini birbirlerinin yerine koyarak, anlamaya çalışırlar" yargısında da katılımcıların büyük çoğunluğu bazen cevabını vermişlerdir. Yedinci sorumuza verilen cevaplar da katılımcıların SH ile GïH çalışanları arasındaki siyasi görüş, kültür vb. farklara karşı hoşgörülü oldukları yönündedir. Çoğu zaman ve bazen şıklarına verilen cevaplar çokluğu dikkat çekmektedir. "SH ile GİH çalışanları, aralarında yüz yüze iletişime önem verirler" yargısına ise verilen cevapların büyük çoğunluğu yine çoğu zaman ve bazen şeklinde olmuştur. "SH ile GİH çalışanları bilgilerini karşılıklı olarak paylaşırlar" yargısına da katılımcıların büyük bir kısmı bazen ve çoğu zaman şeklinde cevaplar vermişlerdir.

Örneklem gurubuna sorulan "SH ile GİH çalışanları sosyal içerikli toplantılarda bir araya gelirler" yargısına da katılımcıların büyük çoğunluğu bazen ve çoğu zaman cevabını vermişlerdir. "SH ile GİH çalışanları arasında, dedikoduya izin vermeyen, olumlu bir iletişim ortamı vardır." Yargısında da bazen ve nadiren şeklinde olmuştur. "SH ile GïH çalışanları arasında, formal iletişimin yanında informal iletişim kanalları da açıktır" yargısına verdikleri cevaplarda diğerlerinden fazla bir fark taşımamıştır. Büyük oranda bazen ve çoğu zaman şeklinde olmuştur. "SH ile GïH, çalışanları iş ve çalışma amaçlarını aynı şekilde anlar ve yorumlar." Yargısına büyük oranda bazen ve çoğu zaman şıkkı en çok verilen cevap olmuştur. Bazen ve çoğu zaman seçeneği katılımcıların büyük çoğunluğu tarafından işaretlenmiştir. "SH ile GİH çalışanları birbirlerinin olumlu davranışlarını öne çıkarmaya çalışırlar." Yargısına verilen cevaplarda büyük ölçüde nadiren ve bazen şeklinde olmuştur. "SH ile GİH çalışanları aralarındaki iletişimde iyi birer dinleyicidirler." Yargısına da verilen cevaplar bazen ve çoğu zaman şeklinde olmuştur.

Sağlık Kurumlarında Sağlık Hizmetleri Sınıfı Ve Genel İdari Hizmetler Sınıfı Personelleri Arasındaki İletişim Sorunları Değişkenine Göre Anlamlı Bir Farkın Olup Olmadığını Belirlemek İçin Yapılan Bağımsız Grup t Testi Sonuçları incelenmiştir. Ayrı tablolar halinde aşağıda sunulmuştur.

Tablo 10: Sağlık Hizmetleri Sınıfı ile Genel İdari Hizmetler Sınıfı çalışanları başarılarını karşılıklı olarak paylaşma durumları

\begin{tabular}{llllll}
\hline Hastanedeki çalışma sınıfı & N & X & SS & F & P \\
\hline
\end{tabular}




\begin{tabular}{llllll}
\hline Sağlık Hizmetleri Sınıfı & 311 & 2,89 & 1,20 & 0,101 & 0,02 \\
\cline { 1 - 3 } Genel İdari Hizmetli Sınıfı & 184 & 2,56 & 1,12 & &
\end{tabular}

$\mathrm{P}<0,05$

Tablo 4.10' da Sağlık kurumlarında çalışan personellerin aralarındaki iletişim sorunlarına göre "Sağlık Hizmetleri Sınıfı ile Genel İdari Hizmetler Sınıfı çalışanları başarılarını karşılıklı olarak paylaşırlar." Bakıldığında sağlık hizmetleri sınıfında $(\bar{X}=2,89)$, genel idari hizmet sınıfında ise ( $\bar{X}$ $=2,56)$ şeklinde görülmektedir.

Katılımcıların arasındaki iletişim sorunlarının anlamlı bir şekilde farklılaşıp farklılaşmadığını test etmek amacıyla bağımsız gruplar için t-testi kullanılmıştır. Analiz sonucuna göre $(\mathrm{p}=0,02)$ sağlık hizmetleri sınıfı ile genel idari hizmetli sınıfı arasında anlamlı bir farklılık bulunmaktadır. $(\mathrm{p}<0,05)$

Tablo 11: Katılımcıların İletişim Sırasında kendilerini birbirlerinin yerine koyarak, anlamaya çalışma durumlarının incelenmesi

\begin{tabular}{llllll}
\hline Hastanedeki çalışma sınıfı & $\mathrm{N}$ & $\mathrm{X}$ & $\mathrm{SS}$ & $\mathrm{F}$ & $\mathrm{P}$ \\
\hline Sağlık Hizmetleri Sınıfı & 311 & 2,91 & 1,21 & 0,011 & 0,018 \\
\cline { 1 - 4 } Genel İdari Hizmetli Sınıfı & 184 & 2,65 & 1,16 & &
\end{tabular}

$$
\mathrm{P}<0,05
$$

Tablo 4.11'de Sağlık kurumlarında çalışan personellerin aralarındaki iletişim sorunlarına göre "Sağlık Hizmetleri Sınıfı ile Genel İdari Hizmetler Sınıfı çalışanları iletişim Sırasında kendilerini birbirlerinin yerine koyarak, anlamaya çalışırlar." Bakıldığında sağlık hizmetleri sınıfında ( $\bar{X}=2,91)$, genel idari hizmet sınıfında ise $(\bar{X}=2,65)$ şeklinde görülmektedir.

Katılımcıların arasındaki iletişim sorunlarının anlamlı bir şekilde farklılaşıp farklılaşmadığını test etmek amacıyla bağımsız gruplar için t-testi kullanılmıştır. Analiz sonucuna göre $(p=0,018)$ sağlık hizmetleri sınıfı ile genel idari hizmetli sınıfı arasında anlamlı bir farklılık bulunmaktadır. $(\mathrm{p}<0,05)$

Tablo 12: Katılımcıların bilgilerini birbirleriyle karşılaştırılması

\begin{tabular}{llllll}
\hline $\begin{array}{l}\text { Hastanedeki çalışma } \\
\text { sınıfı }\end{array}$ & $\mathrm{N}$ & $\mathrm{X}$ & $\mathrm{SS}$ & $\mathrm{F}$ & $\mathrm{P}$ \\
\hline Sağlık Hizmetleri Sınıfı & 311 & 3,22 & 1,13 & 0,793 & 0,043 \\
\cline { 1 - 4 } $\begin{array}{l}\text { Genel İdari Hizmetli } \\
\text { Sınıfı }\end{array}$ & 184 & 3,01 & 1,13 & & \\
\hline $\mathrm{P}<0,05$ & & & &
\end{tabular}

Tablo 4.12'de Sağlık kurumlarında çalışan personellerin aralarındaki iletişim sorunlarına göre "Sağlık Hizmetleri Sınıfi ile Genel İdari Hizmetler Sınıfı çalışanları bilgilerini karşılıklı olarak paylaşırlar." Bakıldığında sağlık hizmetleri sınıfında $(\bar{X}=3,22)$, genel idari hizmet sınıfında ise ( $\bar{X}$ $=3,01)$ şeklinde görülmektedir.

Katılımcıların arasındaki iletişim sorunlarının anlamlı bir şekilde farklılaşıp farklılaşmadığını test etmek amacıyla bağımsız gruplar için t-testi kullanılmıştır. Analiz sonucuna göre $(p=0,043)$ sağlık hizmetleri sınıfı ile genel idari hizmetli sınıfı arasında anlamlı bir farklılık bulunmaktadır. $(\mathrm{p}<0,05)$

Tablo 13: Katılımcıların sosyal içerikli toplantılarda bir araya gelme durumlarının incelenmesi

\begin{tabular}{llllll}
\hline Hastanedeki çalışma sınıfi & $\mathrm{N}$ & $\mathrm{X}$ & SS & F & P \\
\hline
\end{tabular}




\begin{tabular}{llllll}
\hline Sağlık Hizmetleri Sınıfı & 311 & 3,21 & 1,14 & 0,021 & 0,012 \\
\cline { 1 - 4 } Genel İdari Hizmetli Sınıfı & 184 & 2,94 & 1,13 & & \\
\hline $\mathrm{P}<0,05$ & & & &
\end{tabular}

Tablo 4.13'de Sağlık kurumlarında çalışan personellerin aralarındaki iletişim sorunlarına göre "Sağlık Hizmetleri Sınıfı ile Genel İdari Hizmetler Sınıfı çalışanları sosyal içerikli toplantılarda bir araya gelirler." Bakıldığında sağlık hizmetleri sınıfında $(\bar{X}=3,21)$, genel idari hizmet sınıfında ise ( $\bar{X}=2,94)$ şeklinde görülmektedir.

Katılımcıların arasındaki iletişim sorunlarının anlamlı bir şekilde farklılaşıp farklılaşmadığını test etmek amacıyla bağımsız gruplar için t-testi kullanılmıştır. Analiz sonucuna göre $(p=0,012)$ sağlık hizmetleri sınıfı ile genel idari hizmetli sınıfı arasında anlamlı bir farklılık bulunmaktadır. $(\mathrm{p}<0,05)$

Tablo 14: Katılımcıların Genel idari ve hizmet sınıfı çalışanları arasındaki yakın ilişkiyi sürdürme konusunda çaba gösterme durumları

\begin{tabular}{llllll}
\hline $\begin{array}{l}\text { Hastanedeki çalışma } \\
\text { sınıf }\end{array}$ & $\mathrm{N}$ & $\mathrm{X}$ & $\mathrm{SS}$ & $\mathrm{F}$ & $\mathrm{P}$ \\
\cline { 1 - 4 } Sağlık Hizmetleri Sınıfı & 311 & 3,16 & 1,17 & 1,342 & 0,030 \\
\cline { 1 - 3 } $\begin{array}{l}\text { Genel İdari Hizmetli } \\
\text { Sınıfi }\end{array}$ & 184 & 2,92 & 1,22 & & \\
$\mathrm{P}<0,05$ & & & & & \\
\hline
\end{tabular}

Tablo 4.14'de Sağlık kurumlarında çalıșan personellerin aralarındaki iletișim sorunlarına göre "Sağlık Hizmetleri Sınıfı ile Genel İdari Hizmetler Sınıfı çalışanları aralarında yakın ilişki sürdürme konusunda içten bir çaba gösterirler.” Bakıldığında sağlık hizmetleri sınıfında $(\bar{X}=3,16)$, genel idari hizmet sınıfında ise ( $\bar{X}=2,92)$ şeklinde görülmektedir.

Katılımcıların arasındaki iletişim sorunlarının anlamlı bir şekilde farklılaşıp farklılaşmadığını test etmek amacıyla bağımsız gruplar için t-testi kullanılmıştır. Analiz sonucuna göre $(p=0,030)$ sağlık hizmetleri sınıfı ile genel idari hizmetli sınıfı arasında anlamlı bir farklılık bulunmaktadır. $(\mathrm{p}<0,05)$

Tablo 15. Katılımcıların İș ve çalıșma amaçlarını aynı șekilde anlar ve yorumlama durumları

\begin{tabular}{llllll}
\hline Hastanedeki çalışma sınıfı & $\mathrm{N}$ & $\mathrm{X}$ & $\mathrm{SS}$ & $\mathrm{F}$ & $\mathrm{P}$ \\
\hline Sağlık Hizmetleri Sınıfı & 311 & 3,07 & 1,10 & \multirow{2}{*}{1,231} & \multirow{2}{*}{0,038} \\
\cline { 1 - 4 } Genel İdari Hizmetli Sınıfı & 184 & 2,85 & 1,12 & & \\
\hline
\end{tabular}

$\mathrm{P}<0,05$

Tablo 4.15'de Sağlık kurumlarında çalıșan personellerin aralarındaki iletișim sorunlarına göre "Sağlık Hizmetleri Sınıfı ile Genel İdari Hizmetler Sınıfı, iş ve çalışma amaçlarını aynı şekilde anlar ve yorumlar." Bakıldığında sağlık hizmetleri sınıfında $(\bar{X}=3,07)$, genel idari hizmet sınıfında ise ( $\bar{X}=2,85)$ şeklinde görülmektedir.

\section{Sonuc}

Kendi varlığını üretme çabasındaki insan, üretim faaliyetleri sırasında diğer insanlarla sosyal, ekonomik ve politik ilişkiler içerisine girer. İletişim, düşünce bilinç ve dilsel faaliyetlerin üretilmesi, insanların üretim faaliyetlerinin bir parçası ve sonucudur. İnsan diğer canlılardan farklı olarak toplumsal üretim ilişkilerine ve işbölümüne bağlı bir biçimde kendi bireysel ve toplumsal 
varlığını üretir. Bu süreç kaçınılmaz olarak bir dil ve iletişim ilişkisinin doğmasına neden olur. İnsanların arasında kurulan iletişim, tarihsel ve toplumsal koşullara bağlı olarak çeşitli biçimler alır. $\mathrm{Bu}$ biçimlerden en belirgini de günümüzde gelişen teknolojik araçlar vasıtasıyla gelişen şartlarda kitle iletişimidir. Teknoloji ve iletişim çağı diye adlandırabileceğiz 20.yy'da bilgisayar ve teknolojideki akıl almaz gelişmeler sayesinde insanların birbiriyle olan iletişimleri, kayıtları son derece kolay hale gelmiştir.

Kurum başarısının, çalışanın işinden edindiği doyumun niteliğine büründüğü, rekabet koşullarının acımasızlaştığı piyasa şartlarında, çalışanların zamanında ve etkin bir şekilde iletişim kurmaları son derece önemlidir. Öte yandan kurum amaçlarını benimseyen ve bu amaçlara ulaşmak için kendilerinden beklenenin daha da ötesinde çaba sarf eden kurumsal bağlılığ 1 yüksek çalışanlar, kurumun rekabet gücünü arttırmaktadırlar. Aklında herhangi bir soru işareti olmadan, istediği ve ihtiyaç duyduğu bilgiye zamanında ve yeterli miktarda, doğru mecra ile ulaşan çalışanın başta kendine olan güveni, sonrasında da kurumuna olan inanc1 ve bağlılığı artacaktır. Kuruma bağl1lı̆ga ve müşterinin memnuniyetine etki edecek bu durum en temelinde iletişimin olduğu bir gerçektir.

"Memnuniyet içte başlar" felsefesinden hareketle her kurumda çalışan bireylerin önce kendiyle olan iletişimi, sonra çevreyle olan iletişiminin anlatılmaya çalışıldığı çalışmamız sonucunda Sivas Numune hastanesinde, sağlık hizmetleri sınıfı ve genel idari hizmetler sınıfında görev yapan personelin birbirleriyle olan iletişimleri incelenmiş ve birtakım sonuçlar çıkarılmıştır. Elde edilen bu sonuçlar doğrultusunda bazı önerilere yer verilmiştir.

Çalışmamıza konu olan katılımcıların çoğunluğu kadınlardan oluşmaktadır. (Erkeklerin sayısı da azımsanmayacak kadar çoktur çalışmanın tabiatı gereği cinsiyet açısından dengeli olması sağlanmıştır) katılımcılarımızın büyük çoğunluğu 31-35 yaş aralığındadır. Anketimize katılanlardan büyük çoğunluğunun ebe ve hemşireler olduğu görülmektedir. (Tablo 4.3.) örneklem gurubumuzun büyük çoğunluğu sağlık hizmetleri sınıfinda görev yapmaktadır. Katılımcıların büyük çoğunluğunun 5 yıldan daha az süredir meslekte oldukları görülmektedir. (Tablo 4.5.) 6-10 yıl arasında bir süredir bu meslekte olan katılımcı sayımızda azımsanmayacak derecededir.

Katılımcıların büyük çoğunluğu 5 yıldan daha az süredir bu kurumda çalıştığı görülmektedir. Örneklem gurubumuzun büyük çoğunluğu lisans mezunudur. Örneklem gurubumuzun büyük çoğunluğunun daha önce iletişimle ilgili eğitim aldığı görülmektedir. Ölçekte yer alan ve katılımcılara sorulan, SH ile GIHH çalışanları, sorunlarını karşılıklı olarak paylaşırlar, SH ile GİH çalışanları başarılarını karşılıklı olarak paylaşırlar, SH ile GïH çalışanları karşılıklı olarak birbirine saygı gösterirler, SH ile GİH çalışanları karşılıklı olarak birbirlerine güvenirler, SH ile GïH çalışanları, birbirlerine karşı eleştiriye açıktırlar, SH ile GïH çalışanları iletişim Sırasında kendilerini birbirlerinin yerine koyarak, anlamaya çalışırlar, SH ile GİH çalışanları arasındaki siyasi görüş, kültür vb. farklara karşı hoşgörülüdürler, SH ile GİH çalışanları, aralarında yüz yüze iletişime önem verirler, SH ile GİH çalışanları bilgilerini karşılıklı olarak paylaşırlar, SH ile GİH çalışanları sosyal içerikli toplantılarda bir araya gelirler, SH ile GïH çalışanları arasında, dedikoduya izin vermeyen, olumlu bir iletişim ortamı vardır, SH ile GİH çalışanları arasında, formal iletişimin yanında informal iletişim kanalları da açıktır, SH ile GïH çalışanları aralarında yakın ilişki sürdürme konusunda içten bir çaba gösterirler, SH ile GiH, çalışanları iş ve çalışma amaçlarını aynı şekilde anlar ve yorumlar, SH ile GIHH çalışanları aralarındaki iletişimde iyi birer dinleyicidirler, yargılarına örneklem gurubumuzun büyük çoğunluğu bazen ve çoğu zaman şeklinde cevaplar vermişlerdir. Bu tablodaki sonuçlara göre, Sağlık hizmetleri ve genel idari hizmetler sınıfı çalışanlarının arasında bir iletişim problemi olmadığını söylememiz mümkündür. Katılımcıların SH ile GİH çalışanları birbirlerinin olumlu davranışlarını öne çıkarmaya çalışırlar, yargısına verdikleri olumsuz cevaplar çoğunlukta görünse bile olumlu sayılacak cevap seçeneklerine ezici bir üstünlük sağlayamamıştır. Katılımcıların arasındaki iletişim sorunlarının anlamlı bir şekilde farklılaşıp farklılaşmadığını test etmek amacıyla bağımsız gruplar için t-testi kullanılmıştır. Bu test sonucunda farklı iki sınıfın başarılarını karşılıklı olarak paylaşma durumları arasında anlamlı bir ilişki olduğu tespit edilmiştir. $(p=0,02)($ Tablo 4.10$)$ 
Koç (2017) Sağlık kurumlarında iletişimi konu alan çalışması sonucunda katılımcıların \%53'lük kısmını kadınların oluşturduğunu tespit etmiştir. Bizim çalışmamızda da katılımcıların \%54,6's1 kadınlardan oluşmaktadır. Cinsiyet açısından bu çalışma birbirine benzerlik göstermektedir. Çalışmamızda katılımcıların \%43,7'lik kısmının eğitim durumu, lisans olarak tespit edilmiştir. Koç’un çalışmasında ise \%45'lik kısım öğretim mezunudur. Eğitim açısından bu iki çalışma birbirine farklılık göstermektedir.

Yağbasan ve Çakar (2006) yaptığı çalışmasında, hasta ve doktor arasında yaşanan iletişim probleminin nedeni olarak, doktorların mesleki dil kullanmaları aralarında iletişim problemine sebep olmaktadır. Bizim çalışmamızda da sağlık hizmeti sınıfına giren doktorların bilgilerini, genel idari hizmeti görevini yapan personelle paylaştı̆̆ tespit edilmiştir.

Hoşgör (2014), Çalışmasında sağlık hizmeti sınıfında yer alan doktorların diğer çalışanlarla olan saygısını pozitif ve olumlu olarak bulmuştur. Bizim çalışmamızda da buna benzer bir sonuç çıkmış ve SH sınıfının diğer çalışanlara karşı saygı gösterdiği görülmüştür. Bu iki çalışmanın birbirine tezatlık gösterdiği durum ise, bizim çalışmamızda SH sınıfının başarılarını, diğer arkadaşlarıyla bazı durumlarda paylaştığı görülürken, Hoşgörün çalışmasında doktorların başarısını kimseyle paylaşmadığı görülmüştür.

Yapılan çalışmada, sağlık hizmetlerinde hangi pozisyonda olursa olsun personelin kendi içlerinde iletişiminin iyi düzeyde olduğu görülmektedir fakat bu iletişimi daha üst seviyelere taşımak için yetkililer tarafından bir takım çalışmalar yapılabilir.

\section{Kaynakça}

Aslan D., Boztaş, G., Kılıç, E., Öztürk, İ., Erkan, K., Günbey, L., Balcı, M. ve Akın, L. (2004). Bir Spor Merkezine Kayıtlı Olan Kadınların Sağlık-Hastalık Kavramları İle İlgili Görüşleri Ve Sağlık Arama Davranışlarını Etkileyen Faktörler. Erciyes Üniversitesi Sağllk Bilimleri Dergisi, 13(2), 30-38.

Atakan C., (2015), Sağlık Çalışanlarının Stres Düzeylerinin İletişim Üzerine Olan Etkisini Belirlemeye Yönelik Bir Araştırma, Beykent Üniversitesi Sosyal Bilimler Enstitüsü, Yüksek Lisans Tezi, İstanbul.

Ergüden M., (2015), Sağlık Kurumlarında Hasta Hakları Kapsamında Hasta Memnuniyetsizliğini Etkileyen Faktörlerin Analizi, Dokuz Eylül Üniversitesi, Yüksek Lisans Tezi. İzmir.

Ertaş G, (2014), Sağlık Kurumlarında Stratejik Yönetim, Beykent Üniversitesi, Sosyal Bilimler Enstitüsü, Yüksek Lisans Tezi, İstanbul.

Genç H., (2011), Toplam Kalite Yönetimi Dâhilinde Hasta Memnuniyeti Sivas Devlet Hastanesinde Bir Alan Araştırması, Cumhuriyet Üniversitesi, Sosyal Bilimler Enstitüsü Yüksek Lisans Tezi, Sivas.

Hoşgör G. D., (2014), İletişim ve Sağlık İletişimi, Beykent Üniversitesi Sosyal Bilimler Enstitüsü, Yüksek Lisans Tezi, İstanbul.

Karataş., S., (2012), Bilimsel Araştırma Yöntemleri, aves.akdeniz.edu.tr/Image OfByte.. spx ?Resim $=8 \&$ SSNO=13\&USER $=3180$ (erişim, 04.04.2018)

Kavuncubaşı, Ş., (2000), Hastane ve Sağlık Kurumları Yönetimi, Ankara.

Koç G., (2017), Sağlık Kurumlarında İletişim: Sağlık Personeli- Hasta İletişimin Niteliği ve Etkileyen Faktörler (Manavgat Devlet Hastanesi Örneği), Yüksek Lisans Tezi, Antalya. 
Kuzhan H (2009), Bir Sağlık Kuruluşunda Hizmet Kalitesinin Ölçümü ve Hasta Memnuniyetini Etkileyen Faktörler, Dokuz Eylül Üniversitesi Yüksek Lisans Tezi. İzmir.

Örücü E., Kılıç R., Yıldız H., Yıldız B., (2012). Biçimsel Örgüt Yapısının Örgütsel İletişime Etkisi: Bir Kamu Hastanesi Örneği, Akademik Bakış Dergisi, Sayı: 32.

Türkmendağ N., (2012). Sağlık Kurumlarında Üretim Yönetimi, Beykent Üniversitesi, Sosyal Bilimler Enstitüsü Yüksek Lisans Tezi, İstanbul.

Yağbasan, M., Çakar F., (2006), Doktor Hasta İlişkisinde Dile ve Davranışa Dayalı İletişimsel Sorunları Belirlemeye Yönelik Bir Alan Araştırması, Selçuk Üniversitesi Sosyal Bilimler Enstitüsü Dergisi, 15, 595-607

Yüksel A., (2012). Sağlık Kurumları Çalışanlarının Sendikal Örgütlenme Konusundaki Davranışlarının Cinsiyet Temelinde İncelenmesi Isparta ili merkez kamu hastaneleri örneği. Süleyman Demirel Üniversitesi Yüksek Lisans Tezi, Isparta. 